\title{
Autosomal recessive congenital cataract in captive-bred vervet monkeys (Chlorocebus aethiops)
}

Zandisiwe E. Magwebu, Sahar Abdul-Rasool, Jürgen V. Seier and Chesa G. Chauke

\begin{abstract}
Background: The aim of the study was to evaluate the genetic predisposition of congenital cataract in a colony of captive-bred vervet monkeys.

Methods: Four congenital cataract genes: glucosaminyl (N-acetyl) transferase 2 (GCNT2), heat shock transcription factor $4(H S F 4)$, crystallin alpha A (CRYAA) and lens intrinsic membrane protein-2 (LIM2) were screened, sequenced and analysed for possible genetic variants in 36 monkeys. Gene expression was also evaluated in these genes.

Results: Fifteen sequence variants were identified in the coding regions of three genes (GCNT2, HSF4 and CRYAA). Of these variations, only three were missense mutations (M258V, V16I and S24N) and identified in the GCNT2 transcripts A, B and C, respectively, which resulted in a downregulated gene expression.

Conclusion: Although the three missense mutations in GCNT2 have a benign effect, a possibility exists that the candidate genes (GCNT2, HSF4 and CRYAA) might harbour mutations that are responsible for total congenital cataract.
\end{abstract}

\section{1 | INTRODUCTION}

Spontaneous cataract cases have been reported in a number of non-human primates (NHPs) such as vervet monkey, ${ }^{1}$ cynomolgus monkey ${ }^{2}$ and rhesus macaque. 3 In a colony of captive-bred vervet monkeys maintained at Primate Unitand Delft Animal Centre(PUDAC)/SAMRC, six families from the same ancestry origin were observed to present total morphological characteristics of congenital cataract (Figure 1). The onsets of this rare disorder affected both genders and were detected macroscopically at an age between 6 and 8 months. 4 Although the clouding pattern and age of onset were similar, phenotype occurrence was either bilateral or unilateral in some individuals. Independent factors such as microorganisms, diabetes mellitus and calcium concentrations that are known to contribute to cataract development were within normal levels, 4,5 suggesting the development of congenital cataract to be of genetic origin. The parents of the affected individuals were however observed to be asymptomatic, which confirmed that this phenotype was transmitted in a recessivemode.

To date, more than 50 genes have been reported to cause congenital cataract 6 of which GCNT2, CRYAA, HSF 4 and LIM2 are among the genes that are linked to autosomal recessive cataract.7-10 
The GCNT2 gene encodes glucosaminyl (N-acetyl) transferase 2, an enzyme that is responsible for the formation of blood group I antigen. ${ }^{11,12}$ This gene has threetranscripts (A, B and C) with distinctive exon 1. ${ }^{11,13,14}$ The CRYAA gene is among the earliest recognised small heat shock proteins (sHSPs) and plays a structural role in maintaining lens transparency. ${ }^{15}$ The HSF4 is a member of heat shock transcription family and plays a critical role in the lens formation and differentiation. 6,16 Lastly, LIM2 is the intrinsic membrane protein in the lens fibre cells that is responsible for maintaining the normal structure and function of the lens; ${ }^{17}$ however, the function of this gene is not clearly understood. 18 The selected genes are known to play a crucial role in the development of cataract phenotype in humans; however, there are no reported genetic studies using NHP models.

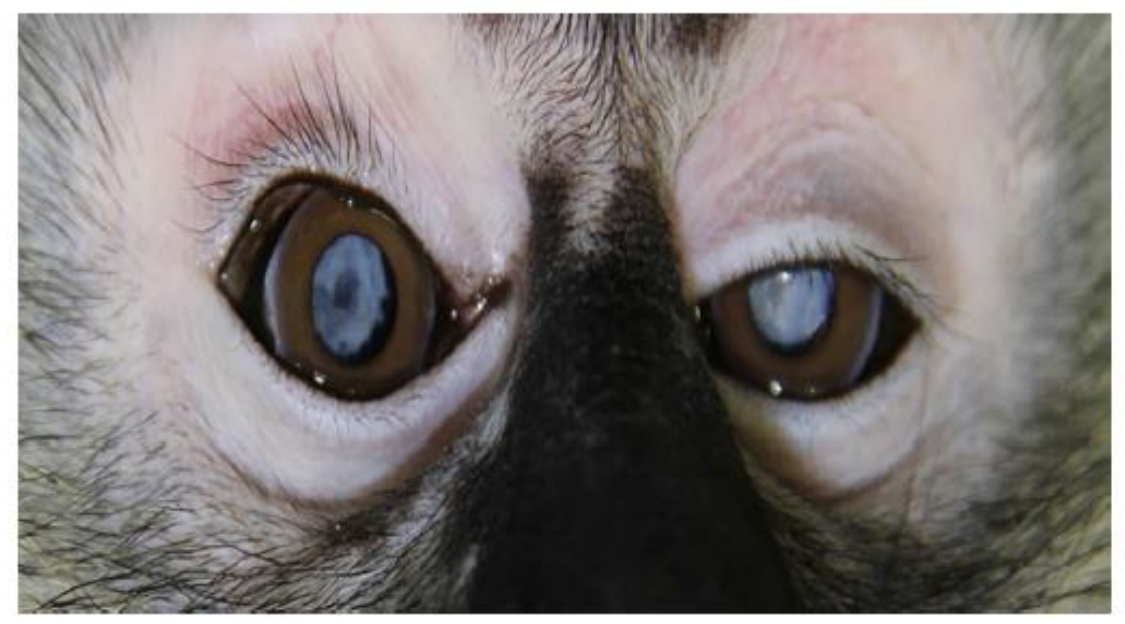

FIGURE 1 Total bilateral congenital cataracts in captive-bred vervet monkeys

The aim of this study was to identify sequence variants in GCNT2, CRYAA, HSF4 and LIM2 genes in cataract captive-bred vervet monkeys using polymerase chain reaction (PCR) and Sanger sequencing. Gene expression was also included to assess whether congenital cataract will have an impact on the activity of these genes. The findings from this project are novel and represent the first genetic report covering the aspects of NHPs autosomal recessive congenital cataract. This study will also assist in managing and improving PUDAC's breeding strategy by excluding cataract carriers as potential breeders.

\section{MATERIALS AND METHODS}

\subsection{Ethical approval and animal selection}

The study was conducted in accordance with the Public Health Service (PHS) Policy on Humane Care and Use of Laboratory Animals (A5726-01). The research protocol (Ref. 10/11) was approved by the Ethics Committee of the SAMRC. Thirty-six captive-bred vervet monkeys were selected based on their family history and cataract morphology. Progeny 9 (Progeny, United Kingdom) was used to construct family pedigrees, and the selected animals were assigned into three groups (12 controls, 12 carriers and 12 cataracts). The control group consisted of healthy animals, whereas the carrier group was asymptomatic parents of cataract individuals which were included as negative and positive controls, respectively, to verify the 
origin of the mutations. Animal housing and maintenance were according to the South African National Standard for the Care and Use of Animals for Scientific Purposes (The SANS 10386:2008); and all animals were fed the same diet of pre-cooked maize meal mixed with a vitamin and mineral concentrate, fresh fruit and water was available ad libitum via an automatic watering device.

\section{2 | Blood collection and DNA extraction}

Blood ( $2 \mathrm{~mL}$ ) was obtained via femoral venipuncture after Ketamine anaesthesia at $10 \mathrm{mg} / \mathrm{kg}$ body weight and collected in EDTA-containing tubes. Genomic DNA was extracted from whole blood using AxyPrep Blood Genomic DNA Miniprep Kit (Axygen Biosciences, USA) according to the manufacturer's instruction.

\section{3 | Candidategene selection}

Four congenital cataract genes were selected and screened for mutations using standard PCR and Sanger sequencing. These genes include GCNT2, HSF4, CRYAA and LIM2) (Table 1). The genome sequences for the prioritised genes were retrieved from the public domain such as NCBI and UCSC genome browser. The specific primers for $\mathrm{HSF}_{4}$ and $C R Y A A$ were designed using NCBI primer design tool (Table 2), while primer sets for $L I M 2^{18}$ and $G C N T 2^{11,12}$ were adopted from previous studies.

\section{4 | PCR amplification}

The PCR consisted of $2 \times$ PCR Master Mix (Promega, USA), DNA template (50 ng) and 0.5 $\mu \mathrm{mol} / \mathrm{L}$ of the upstream and downstream primers. The PCR conditions were performed at $95^{\circ} \mathrm{C}$ for 5 minutes followed by 30 cycles of $95^{\circ} \mathrm{C}$ for 30 seconds, $40-70^{\circ} \mathrm{C}$ (primer dependant) for 30 seconds and $72^{\circ} \mathrm{C}$ for 1 minute, and final extension step was at $72^{\circ} \mathrm{C}$ for 5 minutes. The amplicons were separated by $2 \%$ agarose gel electrophoresis. After PCR amplification, amplicons were further purified using Wizard SV Gel ${ }^{\circledR}$ and PCR clean-up kit (Promega, USA).

\section{5 | DNAsequencing}

The PCR primers for all selected genes were used for bidirectional sequencing which was performed using DNA Sequencer (Applied Biosystems ABI3730xl DNA analyser, USA). Genotyping results were analysed using Chromas lite 2.5.1 and ClustalW by blasting vervet sequence to known reference sequence from NCBI database or UCSC genome browser. The ExPASy translate tool was used to convert nucleotides (DNA) into protein sequence. Additionally, different species were analysed by the CLC Free DNA Workbench 6.0 software (CLC Bio, Denmark) to determine whether the identified mutations were in conserved regions. The possible impact of these mutations on the structure and function of the selected genes was evaluated using PolyPhen-2 prediction tool. 
TABLE 1 Selected autosomal recessive congenital cataract genes

\begin{tabular}{|c|c|c|c|c|c|c|}
\hline Genes & Species & NCBI ID & Chromosome location & Accession number & No. of Exons & References \\
\hline \multirow[t]{6}{*}{ GCNT2 $^{2}$} & \multirow[t]{3}{*}{ Human } & \multirow[t]{3}{*}{2651} & \multirow[t]{3}{*}{$6 \mathrm{p} 24$} & A: NM_145649.4 & \multirow[t]{3}{*}{5} & \multirow[t]{6}{*}{$11,20,29$} \\
\hline & & & & B: NM_001491.2 & & \\
\hline & & & & C: NM_145655.3 & & \\
\hline & \multirow[t]{3}{*}{ Rhesus } & \multirow[t]{3}{*}{697468} & \multirow[t]{3}{*}{4} & A: XM_015135525.1 & \multirow[t]{3}{*}{4} & \\
\hline & & & & B: XM_001087111.3 & & \\
\hline & & & & C: XM_001087231.3 & & \\
\hline \multirow[t]{2}{*}{ HSF4 } & Human & 3299 & $16 \mathrm{q} 22.1$ & NM_001040667.2 & \multirow[t]{2}{*}{15} & \multirow[t]{2}{*}{9} \\
\hline & Rhesus & 698412 & 20 & XM_015126361.1 & & \\
\hline \multirow[t]{2}{*}{ CRYAA } & Human & 1409 & $21 \mathrm{q} 22.3$ & NM_000394.3 & 3 & \multirow[t]{2}{*}{30} \\
\hline & Rhesus & 722370 & 3 & XM_015132801.1 & 3 & \\
\hline \multirow[t]{2}{*}{ LIM2 } & Human & 3982 & $19 \mathrm{q} 13.4$ & NM_030657.3 & 5 & \multirow[t]{2}{*}{8,31} \\
\hline & Rhesus & 719639 & 19 & XM_001116349.3 & 5 & \\
\hline
\end{tabular}

"GCNT2 has three transcripts (A, B and C).

TABLE 2 The list of designed primers for HSF 4 and CRYAA

\begin{tabular}{|c|c|c|c|c|c|}
\hline Gene & Exon & Strand & Sequence & $\begin{array}{l}\text { Length } \\
\text { (bp) }\end{array}$ & $\mathrm{Tm}$ \\
\hline \multirow[t]{6}{*}{ CRYAA } & \multirow[t]{2}{*}{1} & Forward & ССTTAATGCCTCCATTCTGC & \multirow[t]{2}{*}{408} & \multirow[t]{2}{*}{58.4} \\
\hline & & Reverse & GACGGAGCAAGACCAGAGTC & & \\
\hline & \multirow[t]{2}{*}{2} & Forward & ACGTTTGGATTTCAGGTTCG & \multirow[t]{2}{*}{240} & \multirow[t]{2}{*}{55} \\
\hline & & Reverse & AAGGCATGGTGCAGGTGT & & \\
\hline & \multirow[t]{2}{*}{3} & Forward & ACATTTCCCGTGAGTTCCAC & \multirow[t]{2}{*}{749} & \multirow[t]{2}{*}{55} \\
\hline & & Reverse & ATGGAGACAGCACCAGCAG & & \\
\hline \multirow[t]{20}{*}{ HSF4 } & \multirow[t]{2}{*}{4 to 5} & Forward & GGCGGCGTTCTTGGTAGAGCGG & \multirow[t]{2}{*}{419} & \multirow[t]{2}{*}{55.9} \\
\hline & & Reverse & GGACTGGGTCGCAGGAGCAAG & & \\
\hline & \multirow[t]{2}{*}{6} & Forward & ATGAGCAAAGAGGAGGAGGGGTG & \multirow[t]{2}{*}{504} & \multirow[t]{2}{*}{55.9} \\
\hline & & Reverse & CGTGGCTCTGCCGAAGTGTCA & & \\
\hline & \multirow[t]{2}{*}{7 to 8} & Forward & CCCAGCCTCGCCATTCTGTG & \multirow[t]{2}{*}{480} & \multirow[t]{2}{*}{-} \\
\hline & & Reverse & TTCCCGGTGAAGGAGTTTCCA & & \\
\hline & \multirow[t]{2}{*}{9} & Forward & ACACAGGTCCCTGATGCTGGATG & \multirow[t]{2}{*}{164} & \multirow[t]{2}{*}{58.4} \\
\hline & & Reverse & AGGCTCTCCATAAGCCCAGCCAT & & \\
\hline & \multirow[t]{2}{*}{10} & Forward & GTTCTGGCTCTCCCTGTGCCTAC & \multirow[t]{2}{*}{192} & \multirow[t]{2}{*}{60.9} \\
\hline & & Reverse & TCCСССTTACCTCCTGCCATCA & & \\
\hline & \multirow[t]{2}{*}{11} & Forward & TGGTTGAAGCTTTTCTCTGGTGCA & \multirow[t]{2}{*}{313} & \multirow[t]{2}{*}{59.9} \\
\hline & & Reverse & TGTGGGCTGGTAAGGGCTGTT & & \\
\hline & \multirow[t]{2}{*}{12} & Forward & GCCAAAAGCAGTTCTGTCTGCAC & \multirow[t]{2}{*}{179} & \multirow[t]{2}{*}{59.3} \\
\hline & & Reverse & AGACCCCACCAGGTCTCATGC & & \\
\hline & \multirow[t]{2}{*}{13} & Forward & GGCACCACTGACCCAGAGCTC & 147 & 60 \\
\hline & & Reverse & GAGGGCTTGACTCAGCCACCC & & \\
\hline & 14 & Forward & CGGTTCTCACGCAGATGCAGCC & 136 & 59.3 \\
\hline & & Reverse & AGCTCAGCCCAATCACGGCGT & & \\
\hline & 15 & Forward & CATTGGGCGAGAGTGGGGAGGTTAA & 416 & 64.3 \\
\hline & & Reverse & GTCGGGGTAGTGGAGAGAGGCC & & \\
\hline
\end{tabular}

(-) The exon did not work in the selected vervet monkeys. 


\section{6 | Quantitative real-time PCR}

The PAXgene Blood RNA Kit (PreAnalytiX, USA) was used to isolate and purify intracellular RNA from whole blood collected in the PAXgene Blood Tube (BRT). GCNT2 (PPQ03425A), CRYAA (PPQ19536A) and HSF4 (PPH60044C) RT2 ${ }^{2}$ qPCR primer assay designed for SYBR $^{\circledR}$ Green-based real-time PCR (qRT-PCR) were used in this study. A final volume of 25 $\mu \mathrm{L}$ reaction mixture using $12.5 \mu \mathrm{L}$ of $2 \mathrm{X} \mathrm{RT}^{2}$ SYBR Green Rox PCR Master Mix kit (Qiagen, USA), $1 \mu \mathrm{L}$ of $10 \times$ primer stock and $2 \mu \mathrm{L}$ cDNA was prepared in 96-well reaction plates. All standards (1:5) and samples were run in duplicates using universal cycling conditions: $50^{\circ} \mathrm{C}$ for 2 minutes and $95^{\circ} \mathrm{C}$ for 10 minutes, followed by 40 cycles of $95^{\circ} \mathrm{C}$ for 15 seconds and $60^{\circ} \mathrm{C}$ for 1 minute. A melting curve for secondary product detection was included in the qRT-PCR run. Data were analysed with the 7500 Real-Time PCR System SDS software (Applied Biosystems, USA). The amount of each gene was normalised to the average of phosphoglycerate kinase 1 (PGK1: PPQ09326C) and beta-actin (ACTB: PPQ00182A) which were used as housekeeping genes.

\section{3 | RESULTS}

Screening of the coding regions of GCNT2, HSF4 and CRYAA candidate genes revealed 15 sequence variants (Table 3) of which ten were identified in the GCNT2 transcripts. Analysis revealed three silent mutations (G212 > G, H256 > H and N275 > N) and one missense mutation $(\mathrm{M} 258>\mathrm{V})$ in transcript 1A; one missense mutation (V16 > I) in transcript 1B; one missense mutations $(\mathrm{S} 24>\mathrm{N})$ as well as four silent mutations $(\mathrm{S} 15>\mathrm{S}$, S38 > S, I188I and D194 > D) in transcript 1C. Two heterozygous substitutions (c.768T $>\mathrm{C}$ and c.772 $>\mathrm{G}$ ), which resulted in silent $\mathrm{H} 256>\mathrm{H}$ and missense M258 $>\mathrm{V}$ mutation, were respectively identified in transcript $1 \mathrm{~A}$ in families 1 and 2 (Figure 2). These variants were also identified in the mothers (206 and 116) of the affected individuals. Two cataract half-siblings in family 3 (Figure 3) were also sharing a heterozygous substitution (c.46 G>A) with their mother (236) which was observed in codon 16 (V16 > I) of transcript 1B. Furthermore, GCNT2 was down-regulated in cataract-affected individuals compared to the control group (Figure 4).

Furthermore, sequencing of $\mathrm{HSF}_{4}$ resulted in two transition silent sequence variants (R116 > $\mathrm{R}$ and L245 $>\mathrm{L}$ ) which occurred in exon 5 and 10, respectively. The R116 > R was found in all six families, while L245 > L was found in only one cataract individual. Analysis of CRYAA revealed three silent sequence variants in exon $2(\mathrm{P} 82>\mathrm{P})$ and three $(\mathrm{G} 108>\mathrm{G}$ and $\mathrm{S} 169>\mathrm{S})$ which were present in all six families. However, gene expression findings for CRYAA and $\mathrm{HSF}_{4}$ were poorly expressed, inconclusive and were excluded in this report. There were no mutations in LIM2 gene.

\section{4 | DISCUSSION}

The occurrence of the cataract phenotype in the SAMRC captive-bred vervet colony, which was first reported by de Villiers et al,4 provided an opportunity to investigate this rare disorder further in a controlled breeding environment. In this study, six vervet families were affected by total congenital cataract. Although the parents were asymptomatic, most of

\section{http://repository.uwc.ac.za}


them were heterozygous for the identified sequence variants (Figures 2 and 3), thus indicating probably reduced penetrance. Only three families (Figures 2A and $3 \mathrm{~A}$ ) showed missense mutations and the rest had silent mutations. Additionally, this study resulted in the identification of cataract carriers thereby assisting in controlling the breeding programmes. Therefore, the molecular findings from this study further confirmed that congenital cataract in this NHP colony was indeed inherited in a recessive mode. As little is known about the genetic basis of cataract in animals, this study will serve as the first report to identify diseases-causing congenital cataract genes in NHPs.

To date, ten mutations have been reported in GCNT2 gene, which is known to cause adult i phenotype in association with congenital cataract. 19,20 The GCNT2 gene modifies foetal i antigen into active branched adult I antigen, thereby regulating cell growth and differentiation of the eye lens. ${ }^{11,14}$ Two of the GCNT2 transcript (1A and $1 \mathrm{~B}$ ) are more intact in the lens, thus contributing to cataract development while $1 \mathrm{C}$ is responsible for adult $\mathrm{i}$ phenotype. 14 However, mutations in either of the transcript affect the overall activity of GCNT2 resulting in congenital cataract and adult i phenotype. ${ }^{20}$

In this study, three heterozygous missense changes (M258V, V16I and S24N) were located in GCNT2 transcripts A, B and C, respectively. These three variants were found to be benign when blasted on the PolyPhen-2 prediction tool. As the cataract phenotype in this colony is of recessive nature with parents showing reduced penetrance, it is possible that the reported mutations had different phenotypic outcomes or there are other unknown genetic factors contributing to cataract phenotype. Nevertheless, sequencing findings in this study are supported by previous GCNT2 molecular studies, which reported cataract patients with heterozygous mutations in transcript A, B and C.14,20,21 Additionally, the expression of GCNT2 was reduced in the cataract individuals compared to the control group. These findings clearly indicate that GCNT2 is defective in the selected cataract monkeys, and there is a possibility that the gene contributed to the development of total cataract.

The presence of sequence variants in exon $1 \mathrm{C}$ and in exon 3 (Table 3) suggested that the vervet monkeys might also have adult $\mathrm{i}$ phenotype. As the molecular basis of the adult $\mathrm{i}$ phenotype has been identified in humans, 20 the association with congenital cataract requires further clarification in the vervet model. Research thus far is suggesting that the association between these disorders is due to the close linkage of two independent I and cataract-related genes rather than a pleiotropic effect of a gene responsible for adult $\mathrm{i}$ phenotype. ${ }^{14}$ On the contrary, Yu et al ${ }^{14}$ demonstrated that the nucleotide substitutions in cataract individuals are due to a pleiotropic effect of the same mutant gene. Therefore, the second hypothesis might be worth investigating in the vervet colony given that sequence variants were present in transcript $1 \mathrm{C}$. 


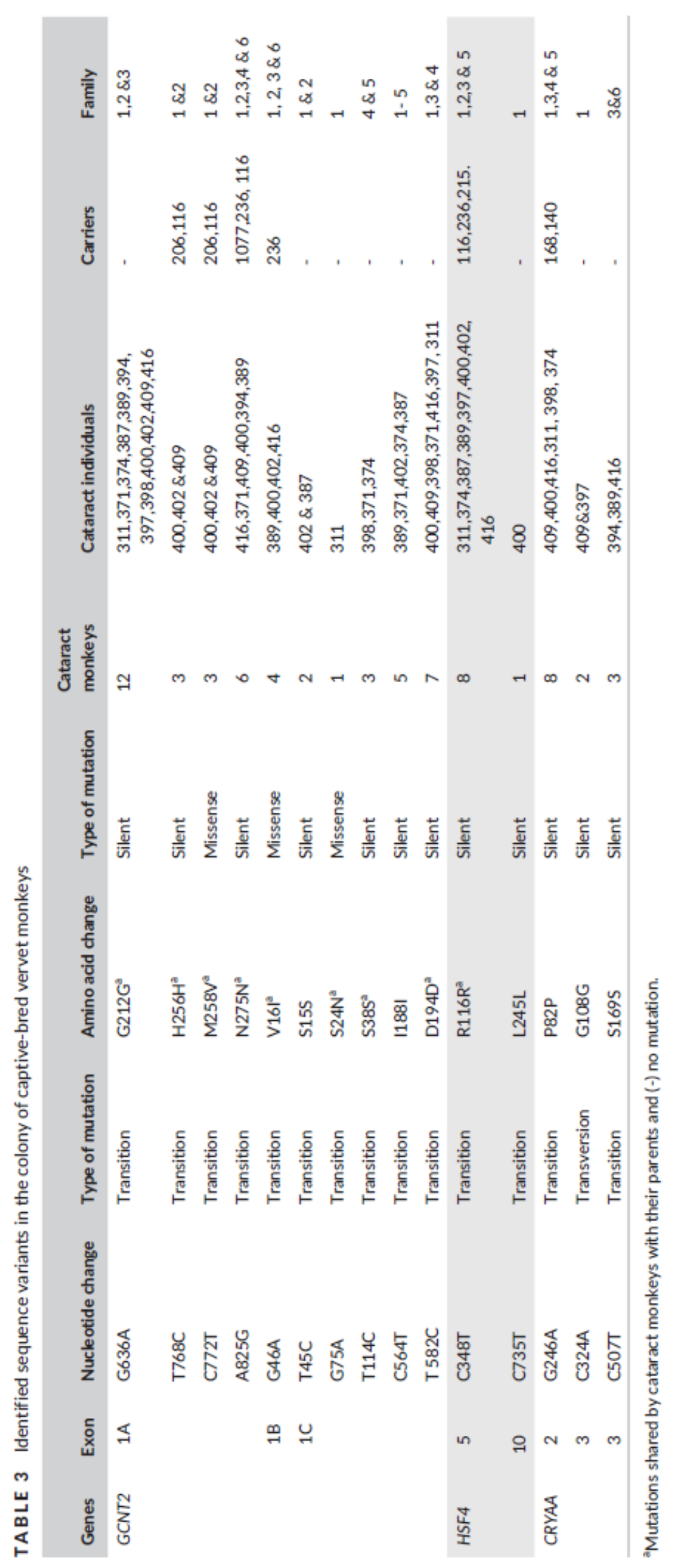




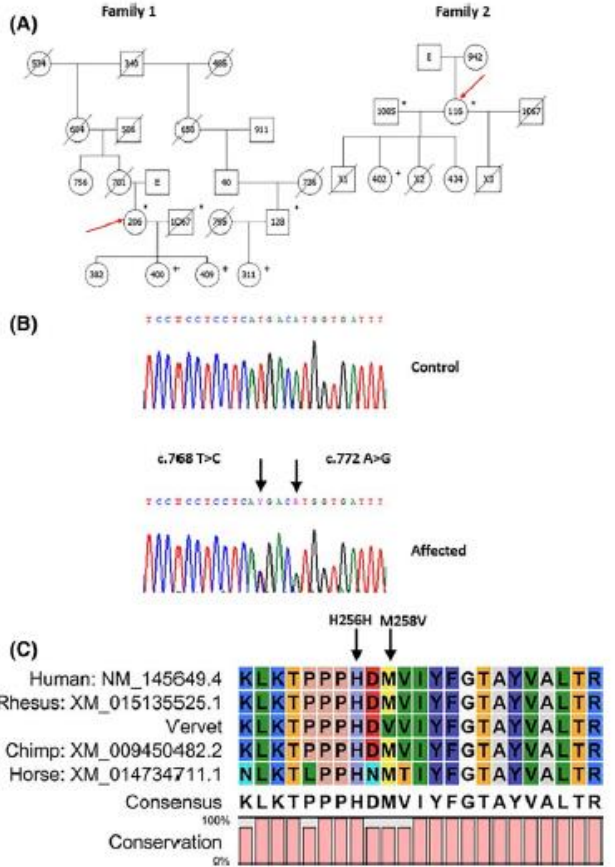

FIGURE 2 Genetic analysis of GCNT2 in captive-bred vervet monkeys. A, Pedigree with family $1(409,400$ and 206$)$ and family 2 (402 and 116) sharing a heterozygous silent (c.772 T>C) and missense (c.768 A>G) mutation. The squares represent males, circles females, $(+)$ cataract individuals, $\left({ }^{*}\right)$ are sequenced carriers and the arrows indicate parents who are carriers for the reported variants. (E) Represent individuals mated with multiple partners. B, Sequence chromatograms showing (arrows) sequence variants found in exon 1 of GCNT2 transcript A. The change at codon $256(\mathrm{H} 256 \mathrm{H})$ and 258 (M258 > V) was found in 409,400, 206, 402 and 116. C, The protein sequence alignment among different species was constructed using CLC DNA workbench
(A)

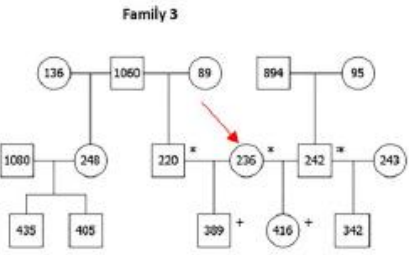

(B)
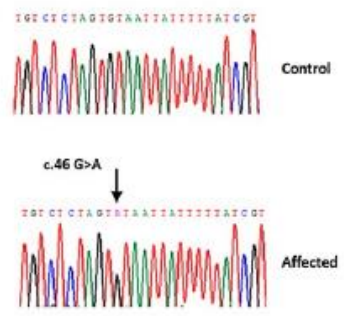

(C) Rhesus: XM_001087111.3 MPLSMRYLFII SVSSVII F IVFS Vervet MPLSMRYLFIIISVSSIIIFIVFS

Chimp: XM 0094504842 MPLSMRYLFI ISVSSVII FIVFS Horse: XM_005603563.2 MRSSMRYLFII SVSCVII FIIVFY Consensus MPLSMRYLF I ISVSSV I IF IVFS Conservation

FIGURE 3 Genetic analysis of GCNT2 in captive-bred vervet monkeys. A, Pedigree with family $3(389,416$ and 236$)$ sharing a heterozygous missense mutation (c.46 G>A). The squares represent males, circles females, $(+)$ cataract individuals, $\left(^{*}\right)$ are sequenced parents and the arrows indicate the mother who is a carrier for the reported variants. B, Sequence chromatogram showing (arrows) sequence variants found in exon 1 of GCNT2 transcript B. The change at codon $16(\mathrm{~V} 16>\mathrm{I})$ was shared by 389,416 and 236 . C, The protein sequence alignment among different species was constructed using CLC DNA workbench

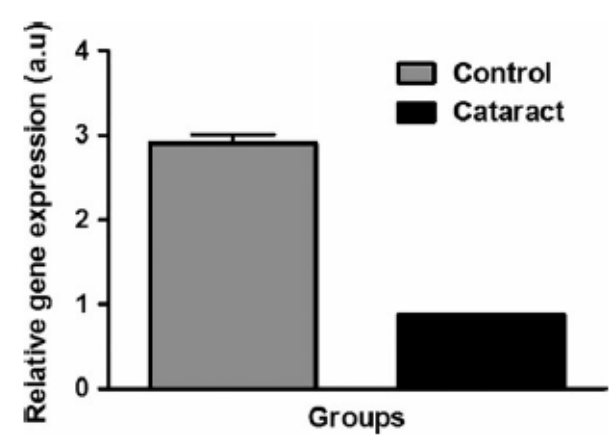

FIGURE 4 GCNT2 mRNA gene expression. The expression of control compared to cataract group. The data were expressed as mean $\pm S D$ and mRNA expression in a.u. (arbitrary units); the bar without error bars, the SD was borderline to zero. "represent significant difference $(P<.05)$

Sequence variants were also identified in $\mathrm{HSF}_{4}$ and $C R Y A A$ in the selected cataract monkeys (Table 3). An interesting observation was made with the location of the HSF4 silent variants (R116R) in the vervet monkey, which is located in the same codon as missense mutation (R116C) in humans and known to be responsible for age-related cataract. ${ }^{22}$ Although both ${ }^{2} S_{4}$ and CRYAA showed silent mutations in this study, their contribution to cataract development is not ruled out due to the accumulating evidence of silent mutations. Based on comparisons between human and chimpanzee, researchers have estimated that $90 \%$ of synonymous mutations are deleterious, 
albeit with weak fitness effects. 23 It has been reported that silent mutation can result in aberrant mRNA splicing, alter secondary structure and affect the rate of translation. ${ }^{24,25}$ Silent mutations can also affect the function of the cell by altering gene expression and regulation. ${ }^{26}$ It has become clear that silent mutations are not entirely neutral genetic passengers and can have some functional consequences. Therefore, their phenotypic contribution needs to be re-evaluated to understand the molecular foundations of their functional importance.

Additionally, sequencing of $\mathrm{HSF}_{4}$ exon 7 and 8 could not be amplified using vervet DNA template; however, it worked with human and rhesus template. This suggests that certain variants such as large-scale deletions and rearrangements might have been overlooked due to the shortfalls of normal sequencing which only detects small-scale variants. ${ }^{27,28}$ It is therefore recommended that more advanced techniques such as multiplex ligation-dependent probe amplification (MLPA) must be considered for future studies.

Nonetheless, it is acknowledged that other unknown genetic factors that are contributing to the cataract phenotype might exist. However, based on the current findings, it can be concluded that the overall effect of the sequence variants in GCNT2, CRYAA and HSF4 may harbour mutations that are responsible for total cataract phenotype in captive-bred vervet monkeys. The mechanism by which the reported missense variants contribute to congenital cataract must be investigated further to determine gene functionality. Additionally, the effect and functionality of the identified synonymous mutations must be re-evaluated to understand their accumulative impact on cataract development in this NHP colony. For future studies, it will be beneficial to screen the entire colony for mutations, and perform epigenetics and gene expression using tissue samples to further strengthen the accumulated findings.

\section{ACKNOWLEDGMENTS}

The study was financially supported by the Primate Unit and Delft Animal Centre (PUDAC) of the South African Medical Research Council (SAMRC). The authors thank Joritha van Heerden, Timothy Collop and Abraham Davids for their excellent technical assistance and expertise in primate management and The University of Stellenbosch for the DNA sequencing services.

\section{ORCID}

Zandisiwe E. Magwebu http://orcid.org/oooo-0oo3-4861-6018 


\section{REFERENCES}

1. Plesker R, Hetzel U, Schmidt W. Cataracts in a laboratory colony of African green monkeys (Chlorocebus aethiops). J Med Primatol. 2005;34:139-146.

2. Sasaki Y, Kodama R, Iwashige S, et al. Bilateral cataract in Cynomolgus monkey. J Toxicol Pathol. 2011;24:69-73.

3. Kessler MJ, Rawlins RG. Congenital cataract in a Free-Ranging Rhesus Monkey. $J$ Med Primatol.1985;14:225-228.

4. De Villiers C, Seier JV, Dhansay MA. Probable genetic origin for a large number of cataracts among captive-bred vervet monkeys (Chlorocebus aethiops). Am J Primatol. 2001;55:4348.

5. Shiels A, Hejtmancik JF. Genetic origins of cataract. Arch Ophthalmol. 2007;125:165-173.

6. Behnam M, Imagawa E, Chaleshtori ARS, et al. A novel homozygous mutation in HSF4 causing autosomal recessive congenital cataract. $J$ Hum Genet. 2015;61:177-179.

7. Kaul H, Riazuddin AS, Yasmeen A, et al. A new locus for autosomal recessive congenital cataract identified in a Pakistani family. Mol Vis. 2010;16:240-245.

8. Riazuddin SA, Yasmeen A, Zhang Q, et al. A new locus for autosomal recessive nuclear cataract mapped to chromosome 19q13 in a Pakistani family. Invest Ophthalmol Vis Sci. 2005;46:623-626.

9. Sajjad N, Goebel I, Kakar N, Cheema AM, Kubisch C, Ahmad J. A novel gene mutation (p. $\mathrm{R} 405 \mathrm{X}$ ) causing autosomal recessive congenital cataract in a large consanguineous family from Pakistan. BMC Med Genet. 2008;9:99.

10. Smaoui N, Beltaief O, BenHamed S, et al. A homozygous splice mutation in the HSF4 gene is associated with an autosomal recessive congenital cataract. Invest Ophthalmol Vis Sci. 2004;45:2716-2721.

11. Pras E, Raz J, Yahalom V, Frydman M, Garzozi HJ, Hejtmancik JF. A nonsense mutation in the glucosaminyl (N-acetyl) transferase 2 gene (GCNT2): association with autosomal recessive congenital cataracts. Invest Ophthalmol Vis Sci. 2004;45:1940-1945.

12. Wussuki-Lior O, Abu-Horowitz A, Netzer I, et al. Hematologic bio-markers in childhood cataracts. Mol Vis. 2011;17:1011-1015.

13. Borck G, Kakar N, Hoch J, et al. An Alu repeat-mediated genomic GCNT2 deletion underlies congenital cataracts and adult i blood group. Hum Genet. 2012;131:209-216.

14. Yu LC, Twu YC, Chou ML, et al. The molecular genetics of the human I locus and molecular background explain the partial association of the adult i phenotype with congenital cataracts. Blood. 2003;101:2081-2088.

15. Su D, Guo Y, Li Q, Guan L, Zhu S, Ma X. A novel mutation in CRYAA is associated with autosomal dominant suture cataracts in a Chinese family. Mol Vis. 2012;18:3059.

16. Cui X, Zhang J, Du R, et al. HSF4 is involved in DNA damage repair through regulation of Rad51. BBA Mol Basis Dis. 2012;1822:1308-1315.

17. Huang B, He W. Molecular characteristics of inherited congenital cataracts. Euro $J$ Med Genet. 2010;53:347-357.

18. Ponnam SPG, Ramesha K, Tejwani S, Matalia J, Kannabiran C. A Missense Mutation in LIM 2 Causes Autosomal Recessive Congenital Cataract. Mol Vis. 2008;14:1204-1208.

19. Lin M, Hou MJ, Yu LC. A novel IGnT allele responsible for the adult iphenotype. Transfusion. 2006;46:1982-1987. 
20.Yu L-C, Twu Y-C, Chang C-Y, Lin M. Molecular basis of the adult i phenotype and the gene responsible for the expression of the human blood group I antigen. Blood. 2001;98:3840-3845.

21. Inaba N, Hiruma $\mathrm{T}$, Togayachi $\mathrm{A}$, et al. A novel I-branching $\beta-1,6-\mathrm{N}-$ acetylglucosaminyltransferase involved in human blood group I antigen expression. Blood. 2003;101:2870-2876.

22. Shi Y, Shi X, Jin Y, et al. Mutation screening of HSF4 in 150 age-related cataract patients. $M o l$ Vis. 2008;14:1850-1855.

23. $\mathrm{Lu} \mathrm{J}, \mathrm{Wu} \mathrm{C}-\mathrm{I}$. Weak selection revealed by the whole-genome comparison of the $\mathrm{X}$ chromosome and autosomes of human and chimpanzee. Proc Natl Acad Sci USA. 2005;102:4063-4067.

24. Sauna ZE, Kimchi-Sarfaty C. Understanding the contribution of synonymous mutations to human disease. Nature Rev Genet. 2011;12:683-691.

25. Shabalina SA, Spiridonov NA, Kashina A. Sounds of silence: synonymous nucleotides as a key to biological regulation and complexity. Nucleic Acids Res. 2013;41:2073-2094.

26.Zhang Z, Miteva MA, Wang L, Alexov E. Analyzing effects of naturally occurring missense mutations. Comput Math Methods Med.2012;2012:1.

27. Herman S, Varga D, Deissler HL, Kreienberg R, Deissler H. Medium-sized deletion in the BRCA1 gene: limitations of Sanger sequencing and MLPA analyses. Genet Mol Biol. 2012;35:53-56.

28. Hogervorst FB, Nederlof PM, Gille JJ, et al. Large genomic deletions and duplications in the BRCA1 gene identified by a novel quantitative method. Cancer Res. 2003;63:14491453 .

29. Irum B, Khan SY, Ali M, et al. Deletion at the GCNT2 locus causes autosomal recessive congenital cataracts. PLoS One. 2016;11:e0167562.

30.Santana A, Waiswo M. The genetic and molecular basis of congenital cataract. Arq Bras Oftalmol. 2011;74:136-142.

31. Irum B, Khan SY, Ali M, et al. Mutation in LIM2 is responsible for autosomal recessive congenital cataracts. PLoS One. 2016;11:e0162620. 